\title{
LOS CONSORCIOS LOCALES EN EL PROYECTO DE LEY DE REGIMEN JURIDICO DEL SECTOR PÚBLICO. REFLEXIONES NECESARIAS
}

\author{
Fernando García Rubio \\ Profesor titular de Derecho Administrativo URJC, técnico de administración general del Ayuntamiento de Madrid \\ fernando.rubio@urjc.es
}

\section{PLANTEAMIENTO. EL PROYECTO DE LEY DE RÉGIMEN JURÍDICO DEL SECTOR PÚBLICO}

La celebración el día 12 de junio de 2015 de un seminario en el INAP sobre los proyectos de ley de Régimen jurídico del sector público y del procedimiento administrativo común, aprobados en el consejo de ministros del 8 de mayo de 2015 y actualmente en tramitación parlamentaria', ha puesto de manifiesto unas profundas y fundamentadas críticas a diversos aspectos de estas nuevas propuestas legislativas desde la más autorizada doctrina científica.

Obviamente analizar ambos proyectos de ley , que constituyen el núcleo fundamental del derecho administrativo recogido por la competencia del art 149.1.18 a de la Constitución , supondría un verdadero tratado y nada más lejos de nuestra vocación al realizar estas líneas.Pero si es nuestra intención recoger algunas de nuestras impresiones sobre un aspecto concreto no abordado en el intenso seminario comentado, pero que entendemos de interés y calado, el nuevo régimen de los consorcios y en concreto de los consorcios locales.

Así el proyecto de Ley, sobre Régimen jurídico del sector público responde al prepósito del desarrollo de las conclusiones de la $\mathrm{CORA}^{2}$, y abarca, por un lado, la legislación básica sobre régimen jurídico administrativo, aplicable a todas las Administraciones Públicas; y por otro, el régimen jurídico específico de la Administración General del Estado, donde se incluye tanto la llamada Administración institucional, como la Administración periférica del Estado.

Esta propuesta legislativa contiene también la regulación sistemática de las relaciones internas entre las Administraciones, estableciendo los principios generales de actuación y las técnicas de relación entre los distintos sujetos públicos. Queda así, en opinión del gobierno (tal y como se desprende de la exposición de motivos del proyecto) sistematizado el ordenamiento de las relaciones ad intra e inter Administraciones, que se complementa con su normativa presupuestaria, destacando especialmente la Ley Orgánica 2/2012, de 27 de abril, de Estabilidad Presupuestaria y Sostenibilidad Financiera, la Ley 47/2003, de 26 de noviembre, General Presupuestaria y las leyes anuales de Presupuestos Generales del Estado.

Así el proyecto de Ley³ establece con carácter básico el régimen jurídico de los consorcios, al tratarse de un régimen que, por definición, afectará a todas las Administraciones Públicas, siguiendo la línea de las modificaciones efectuadas por la Ley 15/2014, de 16 de septiembre, de racionalización del Sector Público y otras medidas de reforma administrativa.

Debe especificarse que la creación de un consorcio en el que participe la Administración General del Estado ha de estar prevista en una ley e ir precedida de la autorización del Consejo de Ministros, circunstancia que por el ca-

\footnotetext{
1 Al respecto vid BOCG-10-A-154-1 Boletín oficial de las Cortes Generales, Congreso de los Diputados Serie A Núm. 154-1 18 de mayo de

2 Con respecto a dicha comisión de reforma administrativa y sus conclusiones puede consultarse a Jose Maria GIMENO FELIÚ “El informe CORA" Heraldo de Aragón, 17 de diciembre de 2013, pág. 19.

3 Debe resaltarse que el 16 de junio de 2015 se presentaron tres enmiendas de totalidad, con petición de devolución del texto , por parte de los grupos parlamentarios en el Congreso de los Diputados de Izquierda plural, Convergencia i Unió y Socialista. Igualmente el 9 de junio finalizó el plazo de presentación de enmiendas al articulado en el Congreso, encontrándose el 16 de septiembre de 2015 en el Congreso a los efectos del art. 90.2. c. e., vid.: www.congreso.es/iniciativas. El texto puede verse en BOCG (Senado) n 597,15 de septiembre 2015 , pp. 125 y ss., habiendo sido aprobado en el pleno de 9 de septiembre de 2015.
} 2015, pág. 61. 
rácter básico de esta disposición afecta a cualquier tipo de consorcio en que esta participación se produzca , independientemente de la administración de adscripción del consorcio , o de la participación que en él tenga el Estado.

Cabe reseñarse, tal y como pretende el proyecto ,que los consorcios se constituyen mediante el correspondiente convenio, al que habrán de acompañarse los estatutos, un plan de actuación de igual contenido que el de los organismos públicos y el informe preceptivo favorable del departamento competente en Hacienda pública o la intervención general que corresponda.

Las entidades consorciadas podrán acordar para los supuestos en que se disuelva la institución, con la mayoría que se establezca en los estatutos, o a falta de previsión estatutaria, por unanimidad, la cesión global de activos y pasivos a otra entidad jurídicamente adecuada con la finalidad de mantener la continuidad de la actividad y alcanzar los objetivos del consorcio que se liquida. Su disolución es automática mediante acuerdo del máximo órgano de gobierno del consorcio, que nombrará a un órgano o entidad como liquidador. La responsabilidad del empleado público que sea nombrado liquidador será asumida por la entidad o la Administración que lo designó, sin perjuicio de las acciones que esta pueda ejercer para, en su caso, repetir la responsabilidad que corresponda.

Esta nueva regulación de los consorcios en el proyecto de Ley de régimen jurídico del sector público es la tercera que afecta en menos de dos años a los consorcios locales, tras las operadas por las Leyes 27/2013, de 27 de diciembre, de racionalización y sostenibilidad de la administración local y 15/2014, de 16 de septiembre, de racionalización del Sector Público y otras medidas de reforma administrativa.

\section{LOS CONSORCIOS. NATURALEZA Y REGULACIÓN}

Se hace necesario antes de profundizar en la próxima regulación de los Consorcios en general y de los de ámbito local en particular, sobre el concepto, características y regulación previa a este proyecto de ley de estas entidades administrativas.

Podemos definir la institución consorcial, desde un punto de vista administrativo siguiendo a REBOLLO PUIG, como "una Administración Instrumental constituida por Administraciones de distinto nivel o por estas y entidades no administrativas sin ánimo de lucro"4. Tiene personalidad jurídica propia y es Administración Pública, aunque una de las consorciadas sea una entidad privada.

Esta definición lógicamente solo abarca a los consorcios locales, toda vez, hasta que la Ley entre en vigor, la única habilitación normativa para esa concepción es la prevista por el hasta este momento vigente art 87 de la LRBRL.

De hecho podemos destacar hasta ahora tres tipos de legislaciones sobre consorcios y así:

El estatal previsto en el art. $6^{\circ}$ de la Ley 30/1992, de 26 de noviembre, sobre Régimen Jurídico de las Administraciones Publicas y del Procedimiento Administrativo Común.

El autonómico derivado de las legislaciones autonómicas correspondientes cada una en su potestad de autoorganización y como parece evidente y prototípico en el caso de los consorcios urbanísticos que tienen dicho régimen jurídico autonómico en su ámbito controlador.

Y finalmente los consorcios locales, tal y como se regulan por la ley andaluza de Autonomía Local, sobre los que más tarde reabundaremos, que en buena medida debe respetar el principio básico estatal.

Esta figura de origen y carácter eminentemente local, previstos en la actualidad por los arts. 57 y 87 de la LR$B R L$, tal y como se han encargado de demostrar entre nosotros los profesores MARTíN MATEO5, LÓPEZ-MUÑIZ ${ }^{6}$ y NIETO GARRIDO', son los Consorcios.

Los Consorcios tienen un carácter claramente institucional , frente a las entidades territoriales y su vocación es la temporalidad para realizar determinadas actividades (obras, gestión de eventos, prestación de servicios etc.), de hecho su éxito como figura de gestión interadministrativa, siendo esta circunstancia de participación de diversas Entidades de naturaleza administrativa en una organización específica su principal característica, ha propiciado su extensión al campo general de todas las Administraciones Públicas, a través de la incorporación de dicha figura en la LRJAPC 30/1992, de 26 de noviembre, especialmente tras su reforma por la Ley 4/1999.

La única singularidad específica de los Consorcios de naturaleza local sobre el resto de figuras consorciales

4 Manuel REBOLLO PUIG “Los consorcios entre entes locales” dentro del anuario del gobierno local dirigido por Tomas Font i LLovet y Alfredo Galan Galan , Fundación Democracia y gobierno local , 1997.

5 Ramón MARTÍN MATEO “Entes locales complejos” Trivium 1987.

6 Jose Luis MARTINEZ LÓPEZ -MUÑIZ “Los consorcios en el derecho español”, IEAL , 1974.

7 Eva NIETO GARRIDO, “El consorcio administrativo”, CEDELS, 1994. 
es la posibilidad de que en el ámbito local se incorporen entidades privadas de carácter no lucrativo (fundaciones y asociaciones principalmente), lo cual no está previsto en la regulación actual de la LRJAPC, ni en la de las CCAA.

De hecho la naturaleza de los Consorcios suele equipararse a la denominada Administración-misión, esto es las organizaciones interadministrativas temporales creadas para la organización de los juegos olímpicos de Barcelona 1992, la capitalidad cultural europea de Madrid en dicho año .o con fines más domésticos el denominado pasillo verde ferroviario para el enterramiento de las líneas férreas en el centro de Madrid. Aunque son utilizados muy frecuentemente para servicios permanentes como el caso de los bomberos(el de Valencia) e incluso para la gestión de espacios feriales(IFEMA)

Una utilización específica de la figura consorcial se realiza a través de la gestión urbanística, que para acelerar las relaciones interadministrativas (fundamentalmente entre Ayuntamientos y Comunidades Autónomas, pero también cuando es propietario de suelo el Estado.) se configura como un modelo mixto de organización y gestión, generando especificidades consagradas en las respectivas leyes urbanística y en especial en la Comunidad de Madrid, donde la Ley 9/2001, de 17 de julio, del Suelo, ha venido ha dar carta de naturaleza jurídica a dichas instituciones ya muy usadas en la práctica habitual de dicha Comunidad. Recuérdese en esa línea la denominada "operación Chamartín" o los Consorcios Getafe Norte, o “Espartales" de Alcalá de Henares, etc.).

Por tanto la naturaleza esencialmente cooperativa, temporal y de grandes operaciones o actuaciones que soporta a los consorcios los hace plenamente compatibles con las Entidades locales, siendo la relación principal de éstas con los referidos Consorcios o figuras consorciales, en su caso la de ser un sujeto más conformador de la creación de éstos, o en caso de ser ajeno los ya clásicas funciones de cooperación y colaboración, puesto que las competencias y actividades previstas para los Consorcios en principio no concurren con las de otras entidades locales.

Igualmente debemos destacar que el Consorcio es una organización creada para gestionar un previo acuerdo de voluntades de diversas Administraciones Públicas, por lo que a diferencia de otras Entidades su propia creación se inspira en el acuerdo y la cooperación, además de la consecución de un fin concreto, siendo los estatutos la norma reguladora que configurará los órganos de gestión, los recursos a aportar, etc.

Este carácter facilitador no obsta para que exceptuados los Consorcios urbanísticos, el uso de estas figuras se reserve para grandes acontecimientos u operaciones que por su envergadura técnica, económica o política no puedan, o no deban, abordarse desde una sola Administración, o para dar el realce necesario a la actuación y la máxima eficacia de la actuación de las Administraciones Públicas con competencias concurrentes en la materia se acuerde crear un Ente único de gestión para dar la máxima agilidad al proyecto.

Podemos concluir en cuanto a la introducción conceptual a los Consorcios que conforme a su actual regulación legal son plenamente complementarios y en algunos casos necesarios, con las EELL territoriales, por lo que su uso y creación no dificulta en ningún caso el establecimiento de una organización supramunicipal, ni en las Comunidades Autónomas pluriprovinciales, ni en las de carácter uniprovincial, siendo por tanto la organización administrativa local de segundo grado que menos problemas plantea a la hora de la implantación de un sistema de elusión de duplicidades ,aunque también es cierto al no estar ubicado en los supuestos del art. $4^{\circ} .2$ de la LRBRL, ni de los arts. 42 a 45 de dicha norma, no puede configurarse en ningún supuesto como Administración Pública territorial ni gozar de potestades, con lo que su ámbito de competencia con otras EELL o de otro tipo, siempre será menor.

De hecho en muchos ámbitos se les ha negó el carácter de Administración Pública que tan sólo quedó claro tras la extensión que de los preceptos de la LCAP 13/1995, de 18 de mayo hizo la Ley 53/1999 a los referidos Consorcios.

En cualquier caso debe destacarse, tal y como apunta HERNANDO RYDINGS ${ }^{8}$, que los consorcios, , han crecido en todos los sectores de forma considerable a partir de mediados de los noventa. Actualmente, podrían existir 1.029 consorcios con participación de entidades locales, cifra que se ha disparado desde mediados de los años noventa, en que había un total de 392 y que mucho dista también de los 61 consorcios que existían en el momento de promulgación de la LRBRL. En este sentido, es muy llamativo para HERNANDO que de los citados 1.029 consorcios, sólo 360 presten servicios mínimos obligatorios. En cuanto a su localización, son las Comunidades Autónomas de Andalucía y de Cataluña, las que ostentan el mayor número de consorcios, contando con 115 la primera y 188 la segunda. Por su parte, en el extremo opuesto, figuran La Rioja con ningún consorcio, la Región de Murcia con tan

8 Maria HERNANDO RYDINGS “Las mancomunidades y los consorcios” págs. 139 a 174 de la obra colectiva “La racionalización de la organización administrativa local”. Civitas Thomson Reuters, 2015, dirigida por Marcos Almeida Cerrada, Claudia Tubertini y Pedro Costa. 
solo uno y Cantabria con dos?.

A pesar de este crecimiento exponencial, las citadas fórmulas consorciadas han carecido de una regulación suficiente que permitiera resolver las dudas que se iban planteando a efectos de cómo debía concretarse su naturaleza jurídica, y, por tanto, su régimen jurídico, desde el momento en que en los mismos pueden aparecer involucradas Administraciones Públicas de distintos niveles.

Los consorcios, como ya hemos apuntado se encuentran regulados a nivel básico hasta el momento, tanto en la LRJPAC como en la LRBRL. Y en este ámbito, ya en la Ley 27/2013, de 27 de diciembre sobre racionalización y sostenibilidad de la administración local (en adelante LRSAL) ya se produjo una modificación ambas normas., de hecho el propio Consejo de Estado en su dictamen 175/2015, sobre el anteproyecto de Ley de régimen jurídico del Sector público, remite en buena medida en el asunto que nos ocupa al dictamen sobre el anteproyecto de ley de la LRSAL y al dictamen sobre el anteproyecto de ley de la LRSP.

Por un lado la $\operatorname{LRSAL}^{10}$ introduce una nueva Disposición Adicional (la número 20) en la LRJPAC y, por otro, modificó el artículo 57 y las Disposiciones Adicionales $9^{\mathrm{a}}$ y $12^{\mathrm{a}}$ de la LRBRL.

Las recogidas en la D.A. $20^{\text {a }}$ de la LRJAPC, al tener carácter básico, resultarán aplicables a los consorcios que sean dependientes de cualesquiera Administraciones Públicas.

Este antecedente enlaza claramente con el actual deseo del legislador por establecer un régimen jurídico básico uniforme. Lo cual debe igualmente colegirse de la nueva reforma operada en virtud de la posterior Ley 15/2014, de 16 de septiembre, de Racionalización del Sector Público (en adelante LRSP), donde igualmente se incluyen previsiones que resultan de aplicación, con carácter básico, a todos los consorcios.

La principal novedad consistió en regular la forma en que las Administraciones Públicas pueden ejercer su derecho de separación del consorcio correspondiente, lo cual, tal y como indica el Consejo de Estado se incorpora al nuevo proyecto de Ley.

Pero, también la LRSAL modifico la LRBRL incluyendo previsiones que afectaban sólo a los consorcios locales.

Tras la nueva D. A. $20^{\text {a }}$ de la LRJPAC, se recogerán los criterios necesarios para concretar el régimen jurídico de los consorcios, que resultaren aplicables a los consorcios que sean dependientes de cualesquiera Administraciones Públicas y ello, además, con independencia de si ya se encontraban constituidos antes de la reforma o no, a tenor de lo establecido en la D. T. $6^{\text {a }}$ LRSAL.

La D. A. $20^{a}$ LRJPAC, en su primer apartado, prevé que serán los Estatutos de cada consorcio los que determinarán la Administración pública a la que queden adscritos, así como su régimen jurídico. No obstante, aunque sea determinada por los Estatutos, la adscripción deberá concretarse, con carácter previo, utilizando los criterios que la propia Disposición fija. Y además siguiendo el orden establecido por la misma.

En este sentido, los dos primeros apartados de la D.A. $20^{\text {a }}$ LRJPAC disponen que:

“1. Los estatutos de cada consorcio determinarán la Administración pública a la que estará adscrito, así como su régimen orgánico, funcional y financiero de acuerdo con lo previsto en los siguientes apartados.

9 Estos datos se recogen en el Informe del Tribunal de Cuentas núm. 1.016 de Fiscalización de los consorcios de ámbito local, 23 de diciembre de 2013, pp. 32 y ss. A su vez, el Tribunal obtiene los datos de la Base de Datos General de Entidades Locales (BDGEL), que no constituye propiamente un registro, sino un instrumento de análisis cuya información, como señala el citado Tribunal, no cuenta con absoluta certeza. A pesar de ello, puede ser de utilidad como aproximación. Resulta llamativo, como apunta el Tribunal, que sea a partir de la promulgación de la Ley 18/2001, de 12 de diciembre, General de Estabilidad Presupuestaria, cuando se constata la creación de un mayor número de consorcios. Así en el trienio 2001-2003 figura en BDGEL que se constituyeron 305 nuevos consorcios, un tercio de los actualmente existentes y ello posiblemente para evitar que las actividades de los consorcios pudieran quedar incluidas en el sector Administraciones Públicas a efectos del sistema de cuentas SEC-95.

10 La ley ha sido objeto de diversos estudios y así por orden cronológico "La reforma de 2013 del régimen local español”, Fundación Democracia y Gobierno Local, 2014, obra colectiva coordinada por Juan Alfonso Santa María Pastor, "La reforma del régimen jurídico de la administración local. El nuevo marco regulatorio a la luz de la ley de racionalización y sostenibilidad de la administración local”, obra colectiva coordinada por Juan Antonio CARRILLO DONAIRE y Pilar NAVARRO RODRIGUEZ, La ley-El Consultor, 2014, igualmente colectiva y dirigida por Tomás QUINTANA LÓPEZ, “La reforma del régimen local. Comentario a la ley 27/2013, de 27 de diciembre, de racionalización y sostenibilidad de la administración local", Tirant lo Blanch, 2014. Igualmente Lorenzo MELLADO RUIZ, "Génesis y realidad de la ley 27/2013, de 27 de diciembre, de racionalización y Sostenibilidad de la administración local: ¿una nueva reforma local?”, CEMCI, 2014, Manuel MEDINA GUERRERO “La reforma del régimen local”, Tirant lo Blanch , 2014, CAMPOS DAROCA, José María, “La reforma de la Ley de bases de régimen local: Ley 27/2013, de 27 de diciembre”, Bosch, 2014 y CEBRIÁN ABELLÁN, Manuel, "El régimen local tras la reforma de la Ley de racionalización y sostenibilidad”, Bosch -Wolters Kluwer, 2014. RODRíGUEZ ARANA, Jaime. "Comentarios a la Ley 27/2013, sobre racionalización y sostenibilidad de la Administración Local”, Comares, 2015; y GARCÍA RUBIO, Fernando (director), "Análisis de las repercusiones de la reforma local sobre la organización, competencias y servicios de la entidades locales", INAP, 2015. 
2. De acuerdo con los siguientes criterios de prioridad, referidos a la situación en el primer día del ejercicio presupuestario, el consorcio quedará adscrito, en cada ejercicio presupuestario y por todo este periodo, a la Administración pública que:

a) Disponga de la mayoría de votos en los órganos de gobierno;

b) Tenga facultades para nombrar o destituir a la mayoría de los miembros de los órganos ejecutivos;

c) Tenga facultades para nombrar o destituir a la mayoría de los miembros del personal directivo;

d) Disponga de un mayor control sobre la actividad del consorcio debido a una normativa especial;

e) Tenga facultades para nombrar o destituir a la mayoría de los miembros del órgano de gobierno;

f) Financie en más de un cincuenta por cien o, en su defecto, en mayor medida la actividad desarrollada por el consorcio, teniendo en cuenta tanto la aportación del fondo patrimonial como la financiación concedida cada año;

g) Ostente el mayor porcentaje de participación en el fondo patrimonial.

h) Tenga mayor número de habitantes o extensión territorial dependiendo de si los fines definidos en el estatuto están orientados a la prestación de servicios, a las personas, o al desarrollo de actuaciones sobre el territorio."

Esta regulación en buena medida se incorpora literalmente en el nuevo artículo 120 del proyecto de Ley.

Así, la citada HERNANDO ${ }^{11}$ afirma que el legislador estatal quizá podría haberse limitado a disponer la obligatoriedad de la adscripción, pero haber dejado margen al legislador autonómico para fijar los criterios correspondientes, ya que la redacción actual puede provocar dudas respecto a su constitucionalidad, parece que la citada D.

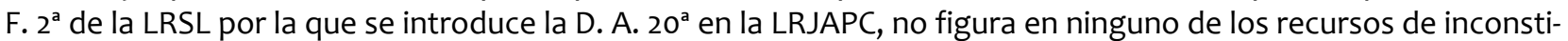
tucionalidad planteados con la citada norma. Opinión esta que choca con el criterio sobre las "bases locales" por el que ha optado el T. C. en su sentencia 103/2013.

De esta forma, resulta que la adscripción del consorcio se realizará a la Administración Pública que cuente con el control orgánico del consorcio el primer día del ejercicio presupuestario y aquel formará parte de sus presupuestos y será incluido en la cuenta general correspondiente (D. A. $20^{\mathrm{a}}$ apartado 4 LRJPAC y ahora art 120 del proyecto). Será el órgano de control de la Administración de adscripción el responsable de llevar a cabo una auditoría de las cuentas anuales del consorcio correspondiente.

La adscripción se prolonga durante todo el ejercicio, aunque se produzcan cambios en el control durante el mismo. Por tanto, la modificación de la adscripción habrá de esperar a la finalización del ejercicio correspondiente, y el consorcio, mientras tanto, continuará figurando en las cuentas de la Administración a la que estaba adscrito inicialmente.

Hay que resaltar que los consorcios deberán estar siempre adscritos a una Administración Pública y ello aunque participen en el mismo entidades privadas sin ánimo de lucro (D. A. $20^{a}$ apartado tercero LRJPAC).

En esa línea y según la indicada HERNANDO'12, la citada Administración de adscripción parece que deberá ser territorial, a tenor de lo establecido en la letra h) del apartado segundo de la citada Disposición al afirmar "tenga mayor número de habitantes o extensión territorial". 
El personal del consorcio ${ }^{13}$ podrá ser funcionario o laboral procedente exclusivamente de la reasignación de puestos de trabajo de las Administraciones participantes y su régimen jurídico será el mismo que el de la Administración de adscripción, no pudiendo superar su retribución la que corresponda a los puestos equivalentes de aquella (D..A. $20^{a}$ apartado quinto LRJPAC).

Este régimen jurídico era aplicable, en el ámbito local a los consorcios que se constituyeran tras la entrada en vigor de la LRSAL. Los constituidos antes de su entrada en vigor, debieron de proceder a adaptar sus estatutos, en el plazo de un año (D..T. $6^{\mathrm{a}}$ LRSAL).

No obstante, si la adaptación implicase cambios en materia de personal o en su régimen presupuestario, contable o de control, el plazo se computará a partir del 1 de enero de 2015 y no a partir de su entrada en vigor. Y como decimos, hay que adaptar los estatutos, salvo que el consorcio correspondiente cumpla las condiciones recogidas en la D.A. $14^{\mathrm{a}}$ en cuyo caso podrá continuar rigiéndose por los mismos ${ }^{14}$.

En el proyecto de ley sobre régimen jurídico del sector público el art 118 establece una definición y concepto legal de la figura analizada y así bajo la rúbrica Definición y actividades propias dispone:

1. Los consorcios son entidades de derecho público, con personalidad jurídica propia y diferenciada, creadas por varias Administraciones Públicas o entidades integrantes del sector público institucional, entre sí o con participación de entidades privadas, para el desarrollo de actividades de interés común a todas ellas dentro del ámbito de sus competencias. 2. Los consorcios podrán realizar actividades de fomento, prestacionales o de gestión común de servicios públicos y cuantas otras estén previstas en las leyes. 3. Los consorcios podrán utilizarse para la gestión de los servicios públicos, en el marco de los convenios de cooperación transfronteriza en que participen las Administraciones españolas, y de acuerdo con las previsiones de los convenios internacionales ratificados por España en la materia. 4. En la denominación de los consorcios deberá figurar necesariamente la indicación «consorcio» o su abreviatura «C».

En cuanto al derecho de separación, cabe señalar que en este ámbito se produce en gran medida una incorporación de las recientes previsiones de la Ley 15/2014, de 16 de septiembre, de Racionalización del Sector Público (en adelante LRSP), así como, las de la LRSAL ${ }^{15}$, en los términos ya indicados.

Así se incluyeron una serie de disposiciones para que cualquier Administración Pública pueda ejercer su derecho de separación del consorcio correspondiente cuando considere que sea la solución más adecuada para la sostenibilidad de las cuentas públicas y se den los requisitos legales para ello. Así la LRSP regula en el art. 12 las causas y el procedimiento para el ejercicio del derecho de separación del consorcio; en el art. 13 los efectos de su ejercicio; el art. 14 regula la liquidación del consorcio y el 15 la adaptación de los estatutos de los consorcios que existieran con carácter previo a la entrada en vigor de la LRSP.

La citada LRSP establece en este tema, tal y como indica HERNANDO' ${ }^{16}$.una regulación cuanto menos confusa y de carácter salomónico (en la vertiente de Bernini de la columnata del baldaquino de San Pedro) se ofrecen todo tipo de facilidades a la disolución de los consorcios. En este sentido, el llamado derecho de separación del consorcio puede ejercitarse por los miembros del consorcio en cualquier momento, siempre que no se haya señalado término para su duración (art. 12.1 LRSP), pero si el consorcio tuviera una duración determinada, sus miembros

13 Sobre esta materia vid. Federico CASTILLO BLANCO “La nueva regulación de los consorcios públicos: interrogantes y respuestas sobre el régimen jurídico de su personal Revista vasca de administración pública n 100 , pags 887 a 920 . el proyecto establece: Artículo 121. Régimen de personal. El personal al servicio de los consorcios podrá ser funcionario o laboral y habrá de proceder exclusivamente de las Administraciones participantes. Su régimen jurídico será el de la Administración Pública de adscripción y sus retribuciones en ningún caso podrán superar las establecidas para puestos de trabajo equivalentes en aquélla. Excepcionalmente, cuando no resulte posible contar con personal procedente de las Administraciones participantes en el consorcio en atención a la singularidad de las funciones a desempeñar, el Ministerio de Hacienda y Administraciones Públicas, u órgano competente de la Administración a la que se adscriba el consorcio, podrá autorizar la contratación directa de personal por parte del consorcio para el ejercicio de dichas funciones

14 Sobre esta norma puede verse Beatriz MORENO SERRANO “Comentario de urgencia la Ley de racionalización del Sector Público y otras medidas de reforma administrativas”, El Consultor de los Ayuntamientos y de los Juzgados, N 19, Sección Actualidad, 23 de Septiembre de 2014, Ref. 1983/2014, pág. 1983, tomo 2.

La propia Exposición de Motivos, apartado III, prevé que: “la presente Ley introduce un régimen jurídico, con carácter básico, sencillo y ex novo del derecho de separación de los miembros del consorcio administrativo y, cuando ello dé lugar a su disolución, se establecen las reglas por las que se regirá. Posteriormente, en la futura Ley de Régimen Jurídico de las Administraciones Públicas, se incluiría un régimen integral (creación, adscripción, funcionamiento, disolución) y básico referido a los consorcios, que derogaría esta regulación y lo previsto en la Ley 27/2013, de 27 de diciembre, de racionalización y sostenibilidad de la Administración Local."

Asimismo, el art. 12.1 in fine, prevé que en el caso de que un municipio deje de prestar un servicio, de acuerdo con lo previsto en la Ley 27/2013, de 27 de diciembre, de racionalización y sostenibilidad de la Administración Local, y ese servicio sea uno de los prestados por el Consorcio al que pertenece, el municipio podrá separarse del mismo.

15 Sobre esta cuestión vid. Francisco TOSCANO GIL “El consorcio administrativo en la encrucijada”, REALA n 3 (nueva época ).

16 Maria HERNANDO RYDINGS, Op. cit., pág. 166 
también podrán separarse del mismo, en el caso, de que alguno de ellos, hubiera incumplido sus obligaciones estatutarias, haciendo especial referencia a las que determinen la imposibilidad de cumplir con el fin para el que fue creado, como es la obligación de realizar aportaciones al fondo patrimonial.

El derecho de separación se efectúa mediante escrito que deberá notificarse al máximo órgano de gobierno del consorcio. El citado escrito deberá recoger el incumplimiento que motiva la separación, la formulación de requerimiento previo de su cumplimiento y el transcurso del plazo otorgado para cumplir tras el requerimiento (art. 12.2 LRASL).

El ejercicio del derecho de separación provoca, como regla general, la disolución del consorcio salvo que el resto de sus miembros acuerden su continuidad y permanezcan en el mismo, al menos, dos Administraciones, dos entidades u organismos públicos vinculados o dependientes a más de una Administración. (art. 13.1 LRASL). De la citada previsión parece que puede mantenerse un consorcio que sólo esté integrado por Administraciones instrumentales, en los términos exigidos en la norma, lo que no parece muy congruente con las considerables limitaciones que la D.A. $9^{\text {a }}$ LRBRL ha incluido respecto de este tipo de consorcios. ${ }^{17}$

Asimismo, conviene apuntar que si el consorcio estuviera adscrito a la Administración que ha ejercido el derecho de separación, tendrá que acordarse por el consorcio a quién, de las restantes Administraciones o entidades u organismos públicos vinculados o dependientes de una Administración que permanecen en el consorcio, se adscribe en aplicación de los criterios establecidos en la Ley (13.2.b) LRSP). Curiosamente parece admitirse aquí que el consorcio pueda quedar adscrito a un organismo público, cuando la D.A. $9^{\text {a }}$ LRBRL limita la adscripción a los organismos autónomos.

Si el derecho de separación no conlleva la disolución del consorcio, se recogen unas reglas en el art. 13.2 LRSP. Por otro lado, el art. 14 se ocupa de regular los efectos de la disolución del consorcio que son la liquidación y extinción del mismo. El art. 15 obliga a que los estatutos de los consorcios recojan las previsiones a las que nos hemos referido, y si el consorcio ya estuviera creado a la entrada en vigor de la misma, aquellos disponen de un plazo de seis meses para realizar la citada adaptación estatutaria.

El régimen jurídico-organizativo de cada consorcio se concreta en su Estatuto (que debe respetar la legislación básica estatal y para los autonómicos y locales además la de cada (CAA), el cual debe determinar los fines para los que se crea, su organización, el régimen de funcionamiento y su régimen de financiación. Los órganos de decisión estarán integrados por representantes de todas las entidades consorciadas en la proporción que se fije en los Estatutos respectivos.

Aunque surgen en el derecho local como instrumento de cooperación, nada impedía que pudieran crearse en el ámbito de otras estructuras administrativas no locales, puesto que el art $4^{\circ}$ de la LRJAPC recoge como uno de los principios de las AAPP dicho principio. En este sentido su extensión a otro ámbitos administrativos se produce, en virtud de la LRJPAC, la cual los regula en su artículo 6.5 (en la versión posterior a la reforma operada en virtud de la Ley 4/1999), a propósito de la gestión de los convenios que puedan celebrar la Administración General del Estado y los Organismos Públicos estatales con la Administración de las Comunidades Autónomas.

Pero, junto con la anterior posibilidad, también existen, como es sabido, consorcios, que no encuentran acomodo, ni en la legislación de régimen local, ni en el citado 6.5 LRJPAC, y tal y como indica FERREIRA ${ }^{18}$, si no en la correspondiente legislación autonómica. de hecho, incluso alguna ley autonómica modula las bases estatales sobre los consorcios locales, como la LAULA, tal y como estudia TOSCANO'19.

Así por citar el ejemplo de los requisitos de adscripción de los consorcios al sector público autonómico para determinar el régimen de control financiero. Puede destacarse, el Decreto Legislativo 1/2000, de 29 de junio, por el que se aprueba el Texto Refundido de la Ley de Hacienda Foral de la Comunidad Autónoma de Aragón, la Ley 14/2006, de 24 de octubre de Finanzas de Cantabria, la Ley 2/2006, de 3 de mayo de Hacienda y del Sector Público de Castilla y León, la Ley 11/2006, de 11 de diciembre de Hacienda de Canarias y la Ley 5/2007, de 19 de abril, de Hacienda de Extremadura.

17 Al respecto vid. Encarnación MONTOYA MARTIN" Medidas de redimensionamiento del sector público instrumental local antes y después de la Ley 27/2013, de 27 de diciembre de racionalización y sostenibilidad de la Administración local”, en Revista General de Derecho Administrativo, $\mathrm{n}^{\circ}$ 36., 2014.

18 Así, como bien apunta Javier. FERREIRA FERNÁNDEZ, “Los consorcios del sector público autonómico. Un instrumento para la gestión conjunta de servicios públicos" dentro del Dereito: Revista xuridica da Universidade de Santiago de Compostela, número extra 1 dedicado a "Estudios sobre la modernización administrativa", 2011 págs. 95-143

19 Francisco TOSCANO GIL, “La definición del consorcio local como entidad local en la legislación autonómica”, Cuadernos de Derecho Local, n²7, págs. 36-47, 2011. 
En el caso de las Leyes 3/2003, de 26 de marzo, de Régimen de la Administración de las Islas Baleares, 15/2004, de 3 de diciembre, de la Administración Foral de Navarra, 9/2007, de 22 de octubre, de Administración de la Junta de Andalucía y 16/2010, de 17 de diciembre, de organización y funcionamiento de la Administración general y del sector público autonómico de Galicia, dicha determinación se establece por la ley autonómica.

Todas estas posibilidades han ocasionado dificultades en la determinación de su naturaleza jurídica y, por tanto, de su régimen jurídico. Sin ánimo de entrar en los diversos planteamientos doctrinales que se formularon en su momento, sí debemos afirmar, que tras la nueva redacción de la LRJAPC operada por la Ley 4/1999 y ante la aparición de un importante número de consorcios, el legislador, tanto estatal como autonómico mostrarán una especial preocupación por esta cuestión, y procederán a facilitar criterios sobre la forma de realizar su adscripción a la Administración pública correspondiente ${ }^{20}$.

No obstante, y a pesar de los esfuerzos realizados, con carácter general, cabe señalar que la regulación y clarificación del consorcio carecía hasta la LRSP de precisión suficiente a los efectos de determinar su adscripción a un ámbito territorial concreto que permitiese conocer con exactitud las normas aplicables relativas a su gestión y control, aunque NIETO GARRIDO ${ }^{21}$ entiende que la introducción de esta modificación en la norma básica en materia de régimen jurídico de las Administraciones Públicas tiene su justificación en la naturaleza no estrictamente local de la entidad consorcial.

En cualquier caso, esta compleja situación parece que ha podido clarificarse a raíz de la reforma operada por la LRSAL (D.F. $2^{\text {a }}$ ) respecto de la LRJPAC. Y es que a través de la nueva D.A. $20^{\text {a }}$ de la LRJPAC, el legislador se ha ocupado de regular el régimen jurídico básico de los consorcios., en cuya línea se profundiza en el proyecto de Ley que ahora se estudia.

De hecho, tal y como afirma TOSCANO ${ }^{22}$ la nueva regulación de los consorcios administrativos, establecida por la LRSAL y la Ley 15/2014, se caracteriza por un incremento de la heterorregulación de su régimen jurídico, que deja menos sitio a la autorregulación por las entidades consorciadas mediante sus estatutos, especialmente, la primera, en bastante menor medida, la segunda. En la medida en que esta heterorregulación se hace a través de normas estatales básicas, no solo se deja menos espacio a la autorregulación por las entidades consorciadas, sino también a la heterorregulación por las Comunidades Autónomas con competencias en la materia.

\section{RÉGIMEN DE LOS CONSORCIOS LOCALES}

Entre los diversos tipos de entidades locales intermunicipales(denominación que ha sido utilizada por Angel SÁNCHEZ BLANCO ${ }^{23}$ y Jose Miguel CARBONERO GALLARDO ${ }^{24}$ ) de carácter supramunicipal sobre cuya diferencia abundaremos mas tarde, debemos destacar, tal y como ha afirmado Alfredo GALÁN GALÁN ${ }^{25}$,entre aquellas entidades de creación potestativa por parte de la Comunidad Autónoma fundamentalmente referido a las Comarcas y a las áreas metropolitanas, con base para el caso andaluz(sobre el que pivotaremos) en el art. 59 a) del Estatuto, aprobado por Ley Orgánica 2/2007, de 19 de marzo, de reforma del Estatuto de Autonomía, esto es la competencia para configurar la organización territorial de la Comunidad Autónoma en atención a razones de interés general de alcance supralocal.

Mientras que por otra parte estarían las agrupaciones voluntarias o asociaciones de municipios y otras entidades locales ,que igualmente con carácter dispositivo recaen en su potestad en el municipio y la provincia ,que son las mancomunidades y en el caso peculiar del ejemplo aquí traído de Andalucía los consorcios locales, basándose estas entidades en la potestad de autoorganización y en la libertad de asociación, tanto de los municipios como de las provincias y lógicamente en el principio de autonomía local .

20 Así, el Tribunal de Cuentas en su Informe núm. 1.016 de Fiscalización de los consorcios de ámbito local, 23 de diciembre de 2013, p. 18, recuerda que en este sentido se manifestó el Informe sobre Reordenación del Sector Público de la Secretaría General de Coordinación Autonómica y Local, del Ministerio de Hacienda y Administraciones Públicas, con fecha de enero 2014, considerando conveniente establecer un marco normativo común regulador de la figura del consorcio, ante la escasa regulación y la heterogeneidad existente es cada ámbito autonómico, sin perjuicio de las especialidades que cada comunidad autónoma pudiera prever que, asimismo, concretase el régimen presupuestario, contable, y de control aplicable. También considera insuficiente la regulación vigente de la figura del consorcio el Informe de la Comisión para la Reforma de las Administraciones Públicas (informe Cora, junio 2013).

21 Así, Eva NIETO GARRIDO, “La Ley de Racionalización y Sostenibilidad de la Administración Local y los consorcios administrativos” dentro de la obra colectiva La Reforma del Régimen Jurídico de la Administración Local La Ley de racionalización y sostenibilidad de la Administración local: Veintitrés Estudios” Thomson-Reuters-Aranzadi , 2014, pág. 372.

22 Francisco TOSCANO GIL, “El consorcio...”, Op. cit., pág. 21.

23 Angel SÁNCHEZ BLANCO, ”Organización intermunicipal”, lustel, 2006.

24 “La Intermunicipalidad en España”, obra colectiva dirigida por José Miguel Carbonero Gallardo, MAP, 2005.

25 Alfredo GALÁN GALÁN “La Organización intermunicipal del Estatuto de Autonomía junto con las Comunidades Autónomas y Gobiernos Locales", págs.,84-86 de la obra colectiva “La organización municipal relaciones institucionales -- Gobiernos Locales”, Instituto Andaluz de Administraciones Públicas ,Sevilla 2008 ,Manuel Zafra Victor (coordinador). 
Todo ello se produce de conformidad a lo dispuesto en el art.63.1 en relación con el 78.1 de la Ley 5/2010, de 11 de junio, de Autonomía Local de Andalucía ${ }^{26}$, norma que desarrolla las disposiciones estatutarias en materia de régimen local.

Y así la LAULA recoge en su art.78.3 al consorcio ${ }^{27}$ como entidad local, circunstancia esta no amparada por la legislación básica estatal ,ni en la redacción anterior a la ley de nacionalización y sostenibilidad, ni en la que se deriva de dicha texto legislativo, puesto que el art. 3 de LRBRL no menciona en ningún momento a los consorcios.

Ahora bien dicha entidad tiene su personalidad jurídica prevista(hasta ahora) expresamente también en la legislación básica estatal en el art. 87 LRBRL, pero dicho otorgamiento de la condición de entidad local o no, no está amparado por la legislación básica estatal, por lo que debe plantearse si el legislador autonómico tiene capacidad en ese sentido, lo cual a parte del caso andaluz, ya referido que tiene su fundamento en el art. 78.3 de la Ley 5/2010, de 11 de junio ,ha sido asumido de forma expresa por la ley 5/1997 de 22 de julio de administración local de Galicia y por la ley 20/2006 de 15 de diciembre municipal y de régimen local de las Islas Baleares.

En cualquier caso entendemos que no existe una contradicción con la legislación estatal vigente, puesto que en el propio texto del art. 3.2 de la LRBRL se hace una remisión a la legislación autonómica, lo que como igualmente ocurre con la existencia de regulaciones de consorcios en otras Comunidades Autónomas, pudiéndose en nuestra opinión distinguir en el régimen jurídico de los consorcios en los tres ámbitos previstos en el apartado II de estas reflexiones.

En ese sentido la propia ley de racionalización y sostenibilidad de la administración local incide en la necesidad de la adscripción de los consorcios a una administración y por tanto su regulación jurídica conforme a la norma de régimen jurídico de esa administración de adscripción, determinándose por el ente que mayor aportación económica realice ,nombre a la mayoría de los miembros del órgano de dirección etc. en una línea muy vinculada a la doctrina del Tribunal de Justicia de la Unión Europea sobre el concepto de entidad publica a los efectos de la contratación.

Conforme esa caracterización la propia ley de racionalización recoge expresamente a los consorcios de las entidades locales en su peculiaridad prevista por el art. 87 LRBRL de presencia de entidades privadas sin ánimo de lucro excluyendo a los efectos de la adscripción la aportación de esas entidades en tanto en cuanto necesariamente deben adscribirse los consorcios a una administración pública.

Por lo que respecta a las propuestas del proyecto sobre el que ahora reflexionamos, debe destacarse que en primer lugar el art 81.3 del proyecto establece : Los organismos y entidades vinculados o dependientes de la Administración autonómica y local se regirán por las disposiciones básicas de esta ley que les resulten de aplicación, y en particular, por lo dispuesto en los Capítulos I y IV y en los artículos 129 y 134, así como por la normativa propia de la Administración a la que se adscriban. Recogiéndose en los arts 82 y 83 unas determinaciones sobre el inventario del sector público, estatal, autonómico y local.

No obstante debe destacarse que, tal y como establece la Disposición transitoria primera, con respecto a la composición y clasificación del sector público institucional estatal prevista en el artículo 84 se aplicará únicamente a los organismos públicos y las entidades integrantes del sector público institucional estatal que se creen tras la entrada en vigor de la ley y a los que se hayan adaptado de acuerdo con lo previsto en la disposición adicional cuarta.

Por tanto, esa obligación si se prescribe para las EELL y CCAA, con una clara ley del embudo, que diría un castizo.

En cuanto al régimen jurídico básico de los consorcios locales que ahora pretende convertirse en supletorio del básico general , generando unas normas básicas de diferente prelación en rango legal(algo inaudito y novedoso) , la LRSAL contiene, una serie de modificaciones que afectaron a los consorcios locales y que se recogieron en la nueva redacción del art. 57. LRBRL, el cual a diferencia del art 87 , no se deroga.

Asimismo, se incluyeron en la ley 27/2013 previsiones que indirectamente afectan también a los consorcios,

26 Acerca de esta Ley autonómica en la materia que nos ocupa vid Concepción BARRERO SÁNCHEZ “Las entidades de cooperación territorial en la Ley 5/2010, de 11 de Junio, de Autonomía Local de Andalucía mancomunidades y consorcios” Nuevas Políticas Públicas: Anuario multidisciplinar para la modernización de las Administraciones Públicas, nº 6, 2010,(Ejemplar dedicado a: La Administración Local renovada de Andalucía), págs. 59-76.

27 Con respecto a esta materia véase Francisco TOSCANO GIL, “La cooperación territorial. Entidades e instrumentos para la cooperación territorial: mancomunidades, consorcios, convenios y redes de cooperación” págs. 293 a 336 de la obra colectiva dirigida por Jose Luis Rivero Ysern “Derecho local de Andalucía”, lustel 2012. 
tales como las del art. 26.2, o las de la Disposiciones Adicionales $9^{\mathrm{a}}$ y $12^{\mathrm{a}}$ de la LRBRL ${ }^{28}$. El artículo 87 , por su parte, no sufrió cambios, siendo su derogación prevista por el proyecto, la gran novedad, tal y como posteriormente pretendemos resaltar.

Debemos recordar que la LRSAL ya determinó la inclusión de dos nuevos apartados en el artículo 57 de la LRBRL, precepto que dispone que la cooperación económica, técnica o administrativa entre la Administración local y las Administraciones del Estado y de las Comunidades Autónomas puede tener lugar, entre otras fórmulas, a través los consorcios o los convenios que se suscriban.

En este sentido, ya la LRSAL estableció un nuevo apartado segundo, con tres premisas que habrán de cumplirse, tanto en la suscripción de convenios como en la constitución de consorcio. Debiendo ambos instrumentos mejorar la eficiencia de la gestión pública, eliminar duplicidades administrativas y cumplir con la legislación de estabilidad presupuestaria y sostenibilidad financiera, recogiéndose la filosofía general de toda esta Ley "racionalizadora"

Por otra parte en el apartado tercero, se procede a añadir una serie de condiciones adicionales que deben cumplir los consorcios locales desde la entrada en vigor de la LRSAL. Así, sólo podrán constituirse cuando la cooperación no pueda formalizarse a través de un convenio. Además se exige que el consorcio, en términos de eficiencia económica, permita una asignación más eficiente de los recursos económicos, y finalmente, que se verifique que la constitución del consorcio no pondrá en riesgo la sostenibilidad financiera del conjunto de la Hacienda Local correspondiente, así como del propio consorcio, el cual no podrá demandar más recursos de los inicialmente previstos. Por todo ello, resulta evidente el objetivo del legislador respecto de éstos: frenar el desmedido ritmo de creación de consorcios que se estaba dando en las últimas décadas, aunque el anterior objetivo tampoco debe ser interpretado de manera absolutamente restrictiva tal y como señala KONNICKX FRASQUET ${ }^{29}$ la limitación debe entenderse por tanto en sus términos precisos, esto es, lo que se pretende es que no se constituyan consorcios incensarios simplemente para organizar determinados eventos, realizar obras, o uso conjunto de inmuebles.

Por otro lado, la LRBRL en su redacción actual también cita a los consorcios en el art. 26.2. recogiendo esta figura junto a la de las mancomunidades, como una de las posibles formulas para articular la prestación de los servicios del art. 26 en aquellos municipios con una población inferior a los 20.000 habitantes., mediante "coordinación Como se ha apuntado más arriba, la Diputación Provincial correspondiente, en su calidad de coordinadora en la prestación de este tipo de servicios, puede proponer que la citada prestación tenga lugar a través de "fórmulas de gestión compartida" (art. 26.2 LRBRL), entre las que cita los consorcios o las mancomunidades, en los términos que hemos estudiado ya en otros trabajos ${ }^{30}$.

Así el Consorcio puede ser otro de los instrumentos de “coordinación” de la prestación de los servicios de los municipios afectados (recuérdese voluntariamente) por esta disposición.

Cabe precisar que si el consorcio se ha constituido con anterioridad a la entrada en vigor de la LRASL y Su

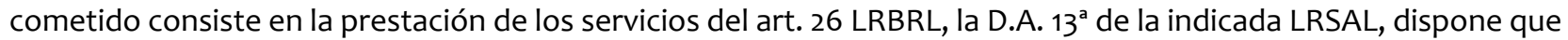
su personal podrá integrarse por quienes no sean personal funcionario o laboral procedente de una reasignación de puestos de trabajo de las Administraciones participantes en el consorcio (D.A. 13 ${ }^{\text {a }}$ LRASL).

Quizá una de las novedades de mayor calado de la LRSAL en estos aspectos, tal y como apunta Hernando Rydings ${ }^{31}$, sea la recogida en la Disposición Adicional 9a LRBL, bajo el título Redimensionamiento del Sector Público Local, y que contiene una batería de medidas que conseguirán muy probablemente adelgazar el sector público, como se podrá comprobar en las líneas que siguen.

En primer lugar, se prohíbe a los entes locales territoriales y a sus organismos autónomos, adquirir, constituir, o participar en la constitución de nuevos organismos durante el tiempo que dure su plan económico-financiero o plan de ajuste (D.A.9 apartado primero LRBRL).

28 No obstante, respecto de la D.A.12 ${ }^{\text {a }}$ de la LRBRL, que se ocupa de las retribuciones en los contratos mercantiles y de alta dirección del sector público local y número máximo de miembros de los órganos de gobierno, nos remitimos a lo señalado en la misma, por cuanto su análisis excede el ámbito del presente trabajo.

29 Amparo KONNICKX FRASQUET, “De nuevo sobre los consorcios" capítulo 14 del libro colectivo coordinado por Manuel J. DOMINGO ZABALLOS “Reforma del Régimen Local.. La Ley de racionalización y sostenibilidad de la Administración local: Veintitrés Estudios” Thomson-Reuters-Aranzadi , 2014. págs. 563 a 602 y en concreto pág. 590.

30 Fernando GARCIA RUBIO "Las entidades supramunicipales en el Gobierno local español. Reflexiones tras la reforma de la sostenibilidad" Cuadernos de derecho local, Número 34, 2014 (Ejemplar dedicado a: La revisión del Gobierno y la Administración local en la Ley 27/2013), págs. 162-195; “La provincia como entidad local. Un análisis tras la Ley de Racionalización” dentro de la obra colectiva coordinada por Juan Alfonso SANTAMARÍA PASTOR “La reforma del 2013 del régimen local español”, Fundación Democracia y gobierno local, $2014 ;$ y “Análisis", op. cit.

31 Maria HERNANDO RYDINGS op. cit. pág. 172. 
En segundo lugar, las entidades que desarrollen actividades económicas, estén adscritas a efectos del Sistema Europeo de Cuentas a cualquier ente local territorial o a sus organismos autónomos y se encuentren en desequilibrio financiero, disponen de un plazo de dos meses para aprobar un plan de corrección de dicho desequilibrio ${ }^{32}$.

Además, los consorcios, entre otras entidades, que estén adscritos, vinculados o sean dependientes, a efectos del Sistema Europeo de Cuentas, a cualquier ente local territorial o a sus organismos autónomos, no podrán constituir, participar en la constitución o adquirir, nuevos entes de cualquier tipología. De esta forma, la norma dispone la prohibición de crear en el futuro entes de segundo nivel, esto es, entidades dependientes de unidades dependientes de las entidades locales territoriales.

Finalmente, el apartado cuarto, exige que los entes que estuvieran controlados por unidades, adscritas, vinculadas o dependientes a efectos del Sistema Europeo de Cuentas, a cualquier ente local territorial o a sus organismos autónomos (entes, por tanto, de segundo nivel) y que no se encuentren en situación de superávit o equilibrio, deberán estar adscritos directamente a las entidades locales territoriales en el plazo de tres meses desde la entrada en vigor de la Ley.

Si no se procede a adscribir el ente ( $y$, por tanto, a incorporarlo a las cuentas de la entidad local territorial correspondiente), aquel deberá ser disuelto. Una vez disuelto, deberá ser liquidado en los tres meses siguientes a la fecha de su disolución. No obstante, si el consorcio estuviera prestando servicios esenciales, los plazos citados se amplían en un año más 33 .

\section{PRINCIPALES DETERMINACIONES CON RESPECTO A LOS CONSORCIOS LOCALES EN EL PROYECTO DE LEY}

Abordando ya la nueva propuesta legislativa en esta materia debe resaltarse que como ya hemos indicado el nuevo régimen jurídico básico de los consorcios se recoge en los arts 118 y siguientes del Proyecto de Ley. Estableciéndose de forma taxativa en el art 119.3 que las normas establecidas en la Ley 7/1985, de 2 de abril, y en la Ley 27/2013, de 21 de diciembre, de racionalización y sostenibilidad de la Administración Local sobre los Consorcios locales tendrán carácter supletorio respecto a lo dispuesto en la regulación legal propuesta. Cuestión que se ha mantenido en el texto pese a la enmienda en contra del PNV34

No obstante esa vocación uniformista de la Ley, que ha sido tachada de inconstitucionalidad por su naturaleza expansiva , no solo para las entidades territoriales con autonomía constitucionalmente amparada , sino para órganos constitucionales, órganos de relevancia constitucional y administraciones independientes, se contemplan en la norma diversas especialidades de los Consorcios locales y así .

a) El artículo 125. al establecer las causas y procedimiento para el ejercicio del derecho de separación de un consorcio determina que los miembros de un consorcio, al que le resulte de aplicación lo previsto en la futurible Ley de régimen jurídico del sector público, o en la Ley 7/1985, de 2 de abril, podrán separarse del mismo en cualquier momento siempre que no se haya señalado término para la duración del consorcio.

Igualmente preceptúa que cuando un municipio deje de prestar un servicio, de acuerdo con lo previsto en la Ley $7 / 1985$, de 2 de abril, y ese servicio sea uno de los prestados por el Consorcio al que pertenece, el municipio podrá separarse del mismo.

b) Obviamente las nuevas determinaciones legales que pretende el proyecto de Ley para los consorcios locales se ven lógicamente acompañados con la correlativa derogación de las disposiciones estatales con rango de Ley estatal, lo cual se plasma en la Disposición derogatoria única que indica:

Derogación normativa. Quedan derogadas cuantas disposiciones de igual o inferior rango se opongan, contradigan o resulten incompatibles con lo dispuesto en la presente Ley y, en especial: a) El artículo 87 de la Ley 7/1985, de 2 de abril, Reguladora de las Bases del Régimen Local. b) El artículo 110 del texto refundido de las disposiciones legales vigentes en materia de Régimen Local aprobado por el Real Decreto Legislativo 781/1986, de 18 de abril.

32 Si la corrección no se cumplía a 31 de diciembre de 2014, la entidad local debe proceder en los seis meses siguientes a la aprobación de las cuentas anuales o de la liquidación del presupuesto del ejercicio de 2014 a disolver cada una de las entidades que continúen en desequilibrio. De no hacerlo, las entidades quedan automáticamente disueltas el 1 de diciembre de 2015. Los plazos citados se amplían en un año si la entidad estuviera prestando los servicios de suministro de aguas , transporte de viajeros o recogida de residuos..

33 El apartado 4, segundo párrafo, de la citada D.A. 9 a de la LRBRL dispone que en el caso de que aquel control no se ejerciese con carácter exclusivo, las citadas unidades dependientes deberán proceder a la transmisión de participación en el plazo de tres meses desde la entrada en vigor de la Ley. Así, por ejemplo el Ayuntamiento de Madrid ha procedido a la supresión de dos consorcios: el de la Escuela Taurina y el de rehabilitación de Teatros.

34 Mantenía ese grupo la supresión del párrafo por excederse de lo básico, vid. enmienda n 49, BOCG (congreso), nº 154.2, pág. 30,18 de mayo de 2015 
La falta de mención expresa del reglamento de servicios de las corporaciones locales, aprobado por Decreto de 17 de junio de 1955, no impide su clara inclusión, en lo que se refiere a los consorcios, para la derogación de todas las determinaciones que contravengan la nueva regulación legal, lo cual para los arts 37 a 40 del indicado RSCL no se hace, pese a la expresa recomendación en ese sentido del Consejo de Estado ${ }^{35}$.

En cuanto a su específico régimen jurídico el art 119 señala que los consorcios se regirán por lo establecido en la propia Ley de régimen jurídico del sector público, tras ella por la normativa autonómica de desarrollo y e tercer lugar por sus respectivos estatutos.

En lo no previsto en dicha Ley, en la normativa autonómica aplicable, ni en sus Estatutos sobre el régimen del derecho de separación, disolución, liquidación y extinción, se estará a lo previsto en el Código Civil sobre la sociedad civil, salvo el régimen de liquidación, que se someterá a lo dispuesto en el artículo 97, y en su defecto, el Real Decreto Legislativo 1/2010, de 2 de julio.

Esta regulación crea una evidente seguridad jurídica pero introduce de soslayo una cierta "mercantilización “ para una entidad de carácter y naturaleza administrativa.

El régimen presupuestario, de contabilidad, control económico-financiero y patrimonial se contempla en el art 122 , manteniéndose un amplio control en ese sentido, en la línea de la LRSAL y de la LO de Estabilidad presupuestaria y sostenibilidad financiera.

Ahora bien la derogación expresa del art 87 LRBRL y del art 110 del TRRL, supone de hecho la incorporación de una cuestión clave, puesto que en el articulado del proyecto que hemos destacado si mantiene la posibilidad de participación de entidades privadas en el seno de un consorcio y así el art 120.3 dispone :

En el supuesto de que participen en el consorcio entidades privadas, el consorcio no tendrá ánimo de lucro y estará adscrito a la Administración Pública que resulte de acuerdo con los criterios establecidos en el apartado anterior.

Esto es el Consorcio en sí no tendrá ánimo de lucro ,pero ¿y los integrantes privados?, esto es la derogación y no incorporación del texto en el proyecto, de la previsión expresa del actual art 87 LRBRL, sobre la limitación de personas jurídico-privadas sin ánimo de lucro, plantea un sinfín de cuestiones.

Partiendo de ese marco general de la regulación de los futuros consorcios hay que ubicar a estas AAPP de carácter mixto; esto es, con participación privada, ya sean municipales o de otras administraciones públicas, dentro de las denominadas fórmulas de colaboración público- privada incentivadas desde la Comisión Europea tras su informe "Comunicación interpretativa de la Comisión relativa a la aplicación del derecho comunitario en materia de contratación pública y concesiones a la colaboración publico-privada institucionalizada (CPPI) (2008/C91/02)”, que plantean una referencia en cuanto al marco de colaboración entre el sector público y el sector privado a los efectos de solventar fines de interés general, circunstancia esta que deriva a su vez del libro verde de la Comisión de 30 de abril de 2004 referente a las diversas formas de colaboración entre las autoridades públicas y el mundo empresarial, cuyo objeto es lógicamente la financiación para los efectos de la construcción, renovación, gestión o mantenimiento de una infraestructura o para la prestación de servicios ${ }^{36}$.

En ese sentido por tanto el marco europeo viene a reforzar la existencia de legislación nacional de carácter básico estatal, tanto en la propia Ley reguladora de las Bases del Régimen Local, como en la Ley de contratos del sector público y en la de las diversas comunidades autónomas y la práctica institucionalizada de ámbito histórico en el aspecto de las entidades locales, a los efectos de la consagración de dichas fórmulas de colaboración.

En cuanto a la configuración de cualquier consorcio mixto de ámbito local, debemos por otra parte distinguir desde un punto de vista administrativo dos tipos de participaciones en dicho sentido: las participaciones en consorcios destinados a la gestión de servicios públicos y las meras participaciones empresariales en cualquier tipo de actividad consorcial conforme ya sea a la habilitación recogida para la administración en el artículo 128 de la Constitución, de ejercicio de la actividad pública económica, que a su vez está expresamente prevista en el Texto Refundido de las disposiciones legales en materia de régimen local para las entidades locales, o de una mera colaboración en la actividad administrativa .

Cabe señalar a los efectos de este tipo de Entidades que pueden existir conflictos con la figura de la empresa mixta , por lo que es necesario precisar el concepto de esta última y así con la STS de 22 de abril de 2005, queda

35 Así, vid el Dictamen 175/2015 de dicho órgano consultivo, pág. 123.

36 A este respecto se puede consultar el citado libro verde en http:// eurolex.europa.eu/Lexurisevuriu /site/es/com/2004/com20040327 eso.PDF 
claro que la LRBRL conceptúa como gestión directa cuando el capital de la sociedad pertenece íntegramente a la entidad local y como gestión indirecta cuando el ente local ostenta una participación parcial. Y es que,

\begin{abstract}
"Los supuestos de sociedades de economía mixta reúnen capital público y capital privado constituyendo uno de los típicos entes instrumentales que atienden a la necesidad de las administraciones de trasladar a otros sujetos el ejercicio de competencias que satisfagan adecuadamente las necesidades colectivas de interés general. De entrada la participación de la administración en el capital social en una determinada proporción compartiendo la gestión ha de calificarse necesariamente como gestión indirecta al no acreditarse que en tal caso exista un control de la administración como pudiera ser la fiscalización e inspección contable, la aprobación por el ente local de su programa de actuación, financiación e inversiones".
\end{abstract}

En este tipo de sociedades de economía mixta podemos destacar, tal y como afirma SANTIAGO IGLESIAS37 ,dos fases a la hora de la constitución de la propia sociedad de economía mixta en los supuestos de que gestione servicios públicos locales: una primera fase se referirá a la elección de la sociedad de economía mixta como modo de gestión y la lógica selección del socio privado y una segunda fase para la constitución de la sociedad.

Así en el caso de los nuevos consorcios el art 124. b) obliga a recoger en los Estatutos respectivos y en el acta de constitución de estos la identificación de participantes en el consorcio así como las aportaciones de sus miembros. A estos efectos, en aplicación del principio de responsabilidad previsto en el artículo 8 de la Ley Orgánica 2/2012, de 27 de abril, los estatutos incluirán cláusulas que limiten las actividades del consorcio si las entidades consorciadas incumplieran los compromisos de financiación o de cualquier otro tipo, así como fórmulas tendentes al aseguramiento de las cantidades comprometidas por las entidades consorciadas con carácter previo a la realización de las actividades presupuestadas.

Debe destacarse el problema de la selección para la participación en el consorcio de las respectivas entidades privadas y el art 123 , remite tan solo a un convenio, sin articular procedimientos de concurrencia y así

Artículo 123. Creación. 1. Los consorcios se crearán mediante convenio suscrito por las Administraciones, organismos públicos o entidades participantes. 2. En los consorcios en los que participe la Administración General del Estado o sus organismos públicos y entidades vinculados o dependientes se requerirá: a) Que su creación se autorice por ley. b) El convenio de creación precisará de autorización previa del Consejo de Ministros. La competencia para la suscripción del convenio no podrá ser objeto de delegación, y corresponderá al titular del departamento ministerial participante, y en el ámbito de los organismos autónomos, al titular del máximo órgano de dirección del organismo, previo informe del Ministerio del que dependa o al que esté vinculado. c) Del convenio formarán parte los estatutos, un plan de actuación, de conformidad con lo previsto en el artículo 92, y una proyección presupuestaria trienal, además del informe preceptivo favorable del Ministerio de Hacienda y Administraciones Públicas. El convenio suscrito junto con los estatutos, así como sus modificaciones, serán objeto de publicación en el Boletín Oficial del Estado.

Las entidades participantes de carácter privado en un consorcio no alteran su condición de administración , puesto que en caso de disolución y pese a la indicada anteriormente aplicación supletoria de la ley de sociedades de capital , las reglas de la disolución de estos solo recogen la recepción por AAPP, o entidades del sector público sus bienes y derechos. Lo mismo es aplicable al personal que solo puede ser funcionario o laboral de las AAPP pertinentes.

Así el art 127.5 especifica que las entidades consorciadas podrán acordar, con la mayoría que se establezca en los estatutos, o a falta de previsión estatutaria por unanimidad, la cesión global de activos y pasivos a otra entidad del sector público jurídicamente adecuada con la finalidad de mantener la continuidad de la actividad y alcanzar los objetivos del consorcio que se extingue. La cesión global de activos y pasivos implicará la extinción sin liquidación del consorcio cedente.

Igualmente la Disposición adicional décima. Sobre Aportaciones a los consorcios, establece que cuando las Administraciones Públicas, o cualquiera de sus organismos públicos, o entidades vinculados o dependientes sean miembros de un consorcio, no estarán obligados a efectuar la aportación al fondo patrimonial o la financiación a la que se hayan comprometido para el ejercicio corriente si alguno de los demás miembros del consorcio no

37 Diana SANTIAGO IGLESIAS, "Las sociedades de economía mixta como forma de gestión de los servicios públicos locales". lustel. Biblioteca de derecho municipal 2010. Págs. 159 a 236. 
hubiera realizado la totalidad de sus aportaciones dinerarias correspondientes a ejercicios anteriores a las que estén obligados. Con un claro plano de desigualdad para los entes privados, en la más pura línea de los privilegios administrativos.

\section{REFLEXIONES SOBRE LA PARTICIPACIÓN DE EMPRESAS PRIVADAS}

Las administraciones públicas como entes personificados, se regulan, tal y como en su día señaló GARCíA DE ENTERRÍA ${ }^{38}$, por el derecho administrativo como derecho estatutario propio de sus relaciones, tanto internas como ad extra, esto es, con la ciudadanía.

Esto hace que el poder público esté sujeto con carácter general a normas jurídicas administrativas, pero debemos destacar que el derecho privado, como en su momento estudió Sebastián MARTíN-RETORTILLO ${ }^{39}$, actúa como norma supletoria de las relaciones jurídico-administrativas. En ese sentido junto a la existencia de instituciones en el derecho privado que son importadas por las administraciones públicas, cabe destacar que tanto las leyes contencioso administrativa 29/1998 (en relación con la Ley de Enjuiciamiento civil 1/2000, de 7 de enero) como el Texto refundido de la ley de Contratos del Sector Público 3/2011, de 14 de noviembre, remiten como normativa supletoria en caso de lagunas en relación con la legislación anteriormente citada de carácter administrativo, a la normativa de derecho privado, esto es a la ley de enjuiciamiento civil y al Código Civil.

Por tanto el derecho privado y los contratos de él derivados, no son en nada ajenos al funcionamiento de las entidades públicas, de hecho el ya apuntado Texto refundido de la Ley de Contratos del Sector Público, aprobado por Real Decreto legislativo 3/2011, de 14 de noviembre, recoge la figura de los contratos privados de la administración, eso sí bajo la doctrina de los actos separables que ya en su momento analizaran García Trevijano y Macera Tiragallo ${ }^{40}$. En ese sentido el art. 20 del indicado TRLCSP, recoge dicha circunstancia, por lo que las entidades administrativas pueden además de ajustar su actividad, como lo hacen en la mayor parte de los supuestos, al ordenamiento jurídico-administrativo, en determinadas ocasiones al ordenamiento jurídico-privado, debiendo así en ese caso renunciar a las potestades de que dicho ordenamiento administrativo les reviste. Aunque no es así en todos los supuestos dado que el art. 44 del Reglamento de bienes de las corporaciones locales, mantiene la potestad de desahucio administrativo para las ocupaciones de bienes patrimoniales de menos de un año.

Partiendo de dicha posibilidad, es cierto que cualquier administración pública tiene la capacidad de contratación y celebración de pactos y acuerdos, sin más límites que el ordenamiento jurídico y el interés general, tal y como recoge el art. 25 del TRLCSP 3/2011, de 14 de noviembre, el artículo 88 en relación con la culminación de procedimientos administrativos de la Ley 30/1992, de 26 de noviembre, sobre Régimen Jurídico de las Administraciones Publicas y del Procedimiento Administrativo Común ${ }^{41} y$ en el caso del ámbito de las entidades locales, conforme a lo dispuesto en el art. 111 del Texto Refundido de las Disposiciones Legales Vigentes en materia de Régimen Local $^{42}$.

Estos pactos y acuerdos que pueden suscribir las entidades administrativas, tienen como ya hemos señalados dos límites, por un lado el ordenamiento jurídico y por otro el interés general y así esa sumisión ante el ordenamiento jurídico, lo entendemos por cualquier tipo de normativa, por supuesto la Constitución y las leyes, pero también cualquier disposición administrativa de carácter general, ya sea de la Administración General del Estado, de las Entidades integrantes de la administración autonómica, o de la administración local.

Cuestión aparte es el interés general como concepto jurídico indeterminado, en tanto en cuanto el interés general se aprecia de una forma u otra por las diversas entidades administrativas.

Partiendo de dicha capacidad, las administraciones, tienen la posibilidad de realizar acuerdos obligacionales, acuerdos que en nuestra opinión se pueden estructurar en tres grandes bloques:

c) Convenios, como acuerdos de voluntades sometidos a un régimen jurídico-administrativo, pero que no tienen un carácter contractual en sentido estricto y así esos convenios expresamente excluidos del ámbito de apli-

38 Eduardo GARCÍA ENTERRÍA MARTINEZ CARANDE y Tomás Ramón FERNÁNDEZ RODRIGUEZ. "Curso de Derecho administrativo I".

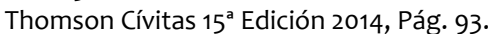

39 Sebastián MARTíN- RETORTILLO BAQUER. “El derecho civil en la génesis del derecho administrativo". Cívitas, 2a edición $1996 .$.

40 José Antonio GARCÍA TREVIJANO “Contratos y actos ante el tribunal supremo: la explotación del hotel Andalucía Palace de Sevilla “Revista de Administración Pública n 28, 1959, págs. 227 y ss y Bernard-Franck MACERA TIRAGALLO. "La doctrina de los actos separables en la contratación administrativa. El ejemplo del derecho francés”. Cedecs. Barcelona 2002

41 Al respecto véase Francisco DELGADO PIQUERAS. "La terminación convencional del Procedimiento administrativo". Aranzadi. 1995. Este precepto se suscribe con variaciones en el art. 86 del proyecto de ley del procedimiento administrativo común, BOCG, 18-5-2015, serie $A, n^{\circ} 155-1$, pág. 40.

42 Normalmente estos acuerdos revisten la fórmula de convenios sobre los cuales puede verse Roberto O BUSTILLO BOLADO “Convenios y contratos administrativos: Transacción arbitraje y terminación convencional del procedimiento" $3^{\text {a }}$ edición Aranzadi-Thomson-Reuters 2010. 
cación de la ley de contratos del sector público por determinación de dicha norma en su art. 4, apartados d) y e), pueden suscribirse, o bien con otras administraciones públicas, esto es, los denominados convenios interadministrativos englobándose en ese sentido también a las entidades institucionales creadas o dependientes de cualquier administración pública, e incluso entes de naturaleza privada pero participados íntegramente por administraciones públicas como las sociedades mercantiles de capital íntegramente público. Y por otro lado podemos hablar de los convenios que se suscriban con entes privados.

En este sentido el Texto refundido de la Ley de Contratos del Sector Público establece a los efectos del ámbito de aplicación de su normativa, que los convenios no pueden ser suscritos en materias objeto de la citada legislación, esto es, en materias que puedan ser sometidas a un contrato público, puesto que además no nos encontramos con medios propios en las administraciones cuando hablamos de entes de naturaleza privada y por tanto e igualmente la posibilidad de excepción del ámbito de aplicación de esta legislación, tal y como ha descrito acertadamente MONTOYA MARTÍN43, toda vez que dicha exención abarca a las sociedades mercantiles de capital íntegramente público. Estableciendo el art. 48.9 de la nueva ley la no aplicación de la regulación sobre carencias de esta a las enmiendas de gestión.

En estos convenios con entes privados, podemos hablar de convenios de colaboración siempre que no se encuentre con materias objeto de contratos públicos sobre dichas materias que sean susceptibles de ser contratadas bajo el amparo de dicha normativa contractual, o uno de los sujetos del convenio pueda ser considerado como medio propio del otro, aunque el nuevo art. 47.1, tercer párrafo de la ley de régimen jurídico abre una puerta peligrosa al indicar: "En tal caso su naturaleza y régimen jurídico se ajustará a lo prvisto en la legislación de control público".

Este elemento nos debe dar una segunda pauta de referencia en relación con los límites para los convenios con entes privados, suscritos por las entidades públicas, esto es, que en dichos convenios no tengan una traza contractual y en cuanto a la prestación de servicios, suministros, etc., y por tanto que la persona jurídica que suscriba el convenio, no tenga una naturaleza mercantil, ya sea en el sentido estricto de las sociedades de capital o cualquier otro ámbito privado que pudiera ser susceptible de un ánimo de lucro, como las sociedades cooperativas, etc. Por lo que los convenios con entidades privadas, se sujetarán siempre a esa segunda limitación no sólo del objeto, sino del sujeto, y no podrá suscribirse convenios con entes privados que sean objeto de prestaciones económicas, puesto que esto impediría la libre concurrencia y mejor oferta con tales entidades mercantiles tal y como se desprendía de las determinaciones de la Directiva 18/2004 de la Unión Europea, sustituida por la actual directiva. No obstante, el art. 47.2.c de la ley de régimen jurídico del sector público sí los permuta, siendo válidos conforme al 48.1 y a lo ya descrito del art. 47.1.

b) La segunda tipología es la de los contratos, que en relación con las administraciones se someten con carácter general a una regulación establecida por remisión de las Directivas de la Unión Europea, a la normativa de contratación pública, esto es, el Texto refundido de la Ley de Contratos del Sector Público, distinguiéndose en dicho ámbito de aplicación, el de los contratos públicos, esto es, de entidades públicas y de los contratos subvencionados, esto es, contratos concertados por entidades privadas pero con fondos íntegramente públicos.

c) El tercer gran bloque de acuerdos y obligaciones de las entidades públicas, es el de los pactos y así podemos hablar de pactos o acuerdos de muy diversa naturaleza, partiendo de los acuerdos con los trabajadores que prestan sus servicios en el sector público y en concreto de las administraciones públicas, tanto funcionarios como laborales, previstos en el Estatuto Básico del Empleado Público, aprobado por ley 7/2007, de 12 de abril en sus arts. 31 y siguientes, los propios convenios colectivos previstos en el Estatuto de los Trabajadores ,que recoge en su art. 82 y siguientes, la figura de los convenios colectivos para los trabajadores de carácter laboral, e incluso para las administraciones públicas, y en tercer lugar los acuerdos de adhesión a convenios que realicen las Federaciones de Municipios, como puede ser la Federación Española de Municipios, y las Federaciones Territoriales de carácter autonómico, que suponen la adhesión por parte de un Ayuntamiento a acuerdos no suscritos por el.

A la vista de esta clasificación de las relaciones obligacionales de las administraciones públicas, se hace necesario avanzar en el concepto del contrato de patrocinio, como contrato regulado por el derecho privado, pero que tiene uso por las entidades públicas evidente y cada vez más importante en el marco de profunda crisis económica, al que se ven enfrentadas las citadas entidades públicas, único fundamento posible en nuestra opinión para la incorporación de empresas a consorcios sin ánimo de lucro.

Así a la hora de precisar el concepto del contrato de patrocinio, es necesario acudir, sin perjuicio de las digresiones doctrinales, al ordenamiento jurídico positivo y en concreto a la ley general de publicidad 34/1988, de 11 de noviembre, que en su artículo 22 establece:

43 Encarnación MONTOYA MARTÍN “Los medios propios o servicios técnicos en la Ley de contratos del sector público : su incidencia en la gestión de los servicios públicos locales “. 2008 , Barcelona. Fundación, democracia y gobierno local 
Artículo 22

El contrato de patrocinio publicitario es aquél por el que el patrocinado, a cambio de una ayuda económica para la realización de su actividad deportiva, benéfica, cultural, científica o de otra índole, se compromete a colaborar en la publicidad del patrocinador.

El contrato de patrocinio publicitario se regirá por las normas del contrato de difusión publicitaria en cuanto le sean aplicables.

Existe una definición positiva más moderna que la recogida en la Ley General de Publicidad, que si bien tiene un carácter específico sectorial, nos puede servir de pauta par profundizar en el concepto de patrocinio en la línea de lo señalado por SÁNCHEZ RUIZ44, que es la contenida en el art. 2 de la Ley 7/2010, de 31 de marzo General de Comunicación Audiovisual, en cuyo punto 29 define al contrato de patrocinio, como "Cualquier contribución que una empresa pública o privada o una persona física no vinculada a la prestación de servicios de comunicación audiovisual ni a la producción de obras audiovisuales haga a la financiación de servicios de comunicación audiovisual o programas, con la finalidad de promocionar su nombre, marca, imagen, actividades o productos."Esta definición es reproducción literal de lo previsto originariamente en el art. 1.k) de la Directiva de Servicios de Comunicación Audiovisual 89/552/CEE, de 3 de octubre de 1980 y 90 en redacción otorgada por la Directiva 2007/65/CEE de 11 de diciembre de 2007.

En ese sentido y fijando el concepto de patrocinio, debemos de hacer una referencia a su equiparación al concepto de esponsorización, que en opinión de la ya señalada SÁNCHEZ RUIZ ${ }^{45}$, es totalmente equiparable a la noción jurídica de patrocinio con el citado concepto de esponsorización, que pese a la regulación específica por la Ley General de Publicidad y por la ya referida Ley General de Comunicación Audiovisual, no ha supuesto un cambio específico para definir el concepto por autores como Díez Picazo ${ }^{46}$.

Dejando al margen estas diferenciaciones semánticas, lo cierto es que los contratos de patrocinio o esponsorización, tienen como principal elemento diferencial de otras modalidades contractuales, tanto en el sector público como en el sector privado, la ausencia de una retribución económica por la prestación de un servicio del contratante, puesto que es un contrato bilateral y tiene naturaleza contractual en tanto en cuanto está definido expresamente tanto en la Ley General de Publicidad 34/1988, de 11 de noviembre en su art. 22, como la ya definida Ley General de Comunicación Audiovisual, art. 2.29, como contrato.

Cabe en ese sentido analizar por tanto esa falta de contraprestación económica directa en la realización del servicio, lo cual pudiera variar la concepción original de contratos prevista por el art. 1254 del Código Civil, que recuérdese es la prestación de servicio a cambio de "dinero o signo cierto que lo represente".

En primer lugar debemos recordar que la redacción del Código Civil es supletoria de la legislación especial, en este caso la Ley General de Publicidad, pero que igualmente esta regulación data de 1889, por lo cual su concepción debe de interpretarse en el contexto social y jurídico actual.

Cabe por otro lado señalar que la prestación del servicio puede tener un contenido económico que no sea directamente abonable o equiparable a una cantidad en dicha contraprestación y en ese sentido debemos recordar, con respecto a los contratos de patrocinio suscritos en el ámbito de las administraciones públicas, el informe de la Junta Consultiva de Contratación Administrativa del Estado 33/1997, de 10 de noviembre, que si bien es anterior a la Ley de Contratos del Sector Público, tanto en su versión original, como obviamente al TRLCSP, abarca perfectamente la concepción y naturaleza de las determinaciones previstas por esta normativa a los efectos que nos referimos.

En ese sentido y en relación con los convenios de colaboración, la otra figura generadora de obligaciones que pudiera suscribirse al efecto de la culminación de la actuación de patrocinio, que la indicada Junta consultiva estatal ha señalado es con respecto a que el pago del precio por parte de la administración no constituye un elemento esencial definidor de la figura contractual, como claramente demostraba el art. 11.2.c) de la Ley de Contratos de las administraciones Públicas 13/1995, de 18 de mayo, al referirse como uno de los requisitos necesarios para la

44 Mercedes SÁNCHEZ RUIZ. "Contrato de patrocinio". Capítulo V de "Los contratos publicitarios". Obra colectiva coordinada por Emilio J. Lázaro Sánchez. Thomson Reuters, Fundación Séneca de la Región de Murcia. 2011. y en concreto Pág. 262

45 Mercedes SÁNCHEZ RUIZ. Op. Cit. Pág. 262.

46 Luis DíEZ PICAZO. “El contrato de esponsorización” ACD 1994, Pág. 9; y Elena VICENTE DOMINGO. (Pág. 43-46), “El contrato de esponsorización” Cintas 1998. 
celebración de contratos a la existencia de crédito adecuado y suficiente "si del contrato se derivan obligaciones, de contenido económico para la administración".

En dicha línea reiteradamente aludida, la citada Junta Consultiva afirma que la figura del contrato sin la obligación de pagar precio, por parte de la administración, tiene amplia acogida en el contrato de gestión de servicios públicos, en aquel momento regulado en el Título II del Libro segundo de la Ley de Contrato de las Administraciones Públicas y en la actualidad por los arts. 8 y 19 del Texto refundido de la ley de Contratos del Sector Público 3/2011, de 14 de noviembre, y en algunos otros tipos contractuales como los contratos de servicios de cafetería y comedor, en los que, no pagando ese precio por la administración, se ha considerado por dicha Junta de verdaderos contratos objetos, al menos en su preparación y adjudicación a la legislación de contratos, tal y como afirmó en sus informe de 10 de julio de 1991 (Expt. 14/91) y de 7 de marzo de 1996 (Expt. 5/96)., y máxime a la vista de lo indicado en el art. 47.1 de la ley de régimen jurídico.

Por tanto debemos señalar que a la suscripción de un contrato de patrocinio, no necesariamente el que no exista un pago por parte de la administración contratante, implica que no exista una relación contractual, puesto que la propia legislación aplicable, (Ley General de Publicidad, etc.) y de la doctrina de la Junta Consultiva aludida, nos encontramos que existe algún tipo de relación obligacional que tiene en sí mismo un contenido económico susceptible por tanto de ser considerado como contrato.

Ahora bien puede una empresa privada implicarse en un consorcio para prestar servicios públicos , sin que se realice publicidad (directa o indirecta) de su marca?., entendemos que pese al auge de la responsabilidad social corporativa , es muy anormal que las empresas , por su legítimo ánimo de lucro, participen en el interés general por mero altruismo.

Por tanto la selección mediante convenio, esto es de forma directa y excluyéndola del ámbito de las garantías de I derecho comunitario en materia de selección de "partners", prevista en el texto exige de una profunda revisión , sino de un mantenimiento del texto del actual art 87 LRBRL.

\section{CONCLUSIONES}

Esas pretensiones del nuevo texto legal no pueden más que calificarse como uniformadoras y con una pretensión reglamentista, que no básica, al regular el detalle más nimio de la organización de los consorcios , sin excluir ni tan siquiera , tal y como le expuso al gobierno muy razonadamente el propio Consejo de Estado los consorcios interautonómicos.

Así una primera crítica al respecto es la falta de margen para la actuación del legislador autonómico, cercenándose tanto potestad autónoma de auto organización (recuérdese la STC 50/1999), como sus competencias sobre régimen local.

No obstante y en aras a la verdad y tras las determinaciones de la LRSAL y de la LRSP, lo cierto es que el proyecto de Ley que nos ocupa no recoge especiales novedades en materia de consorcios, frente a dichas normas , que prácticamente traslada o "refunde" en el conjunto del articulado y además la más reciente jurisprudencia del Tribunal Constitucional ampara aspectos básicos tan extensos como el que se pretende de los Consorcios y así la STC 103/2013 no consideró inconstitucional la remisión del régimen de las Entidades públicas empresariales locales a las previsiones de la estatal LOFAGE 6/1997.

A la vista del texto que ha remitido el gobierno a las Cortes Generales debemos destacar, que la regulación general básica de todo tipo de consorcios, si bien es loable, genera diversas complicaciones en los de actuación y regulación local por la preferencia de esta nueva norma, sobre el que se mantendría vigente art 57 LRBRL.

Por otra parte la derogación y no incorporación al nuevo texto de la limitación a entidades privadas sin ánimo de lucro a los consorcios, posibilita la integración en estos de empresas, lo cual además de una novedad de calado y que casa poco con el mantenimiento de su naturaleza administrativa (el interés general del art 103.1 de la Constitución es poco compatible con los legítimos intereses particulares de las empresas), puede generar colisiones con otras instituciones como las empresas mixtas y los patrocinios.

Esta circunstancia de empresas privadas integrantes de consorcios sin ánimo de lucro puede generar problemas de colisión con otras empresas y con la selección de los integrantes fácilmente evitables con el mantenimiento del régimen actual, o con la incorporación al exhaustivo régimen jurídico básico de los consorcios de unas reglas de selección de las entidades privadas que tengan ánimo de lucro. 